\title{
Rekomendasi Perbaikan Infrastruktur TI SMK Berdasarkan Evaluasi Tingkat Kematangan Framework COBIT 5
}

\author{
Hendrik Kusbandono ${ }^{1 *}$, Dwiyono Ariyadi ${ }^{2 * *}$ \\ * Teknologi Informasi, Politeknik Negeri Madiun \\ ** Teknik Informatika, Universitas Muhammadiyah Ponorogo \\ h3ndrik57@pnm.ac.id ${ }^{1}$, dwiyono_ariyadi@umpo.ac.id ${ }^{2}$
}

\begin{tabular}{l}
\hline \hline Article Info \\
\hline Article history: \\
Received : 08-11-2018 \\
Revised : 16-11-2018 \\
Accepted : 03-12-2018 \\
\hline
\end{tabular}

Keyword:

APO07,

BAI09,

IT Infrastructure,

COBIT 5,

Improvement Recommendations

\begin{abstract}
Starting from 2017, the management policy and education authority of Vocational High School in district region is taken over by the provincial government. In order to distribute the services to Vocational High School in several regions, the provincial government applies data service in online. To support online data service between the provincial education office and the Vocational High School in several regions, it is needed the supports of adequate IT infrastructure. The IT infrastructure components cover human resources and IT assets in form of hardware and software. To discover the maturity level of IT infrastructure in each Vocational High School, it is required analysis of IT human resources capability and IT asset owned. The research method used was COBIT 5 framework with a set of best practices which able to facilitate the management to assess and mitigate risks, as well as provide improvement recommendations. Subdomain focus used for evaluations and recommendations were APOO7 and BAI09. The results obtained by capability level of each subdomain is at level 1 namely Performed Process that organization performs a process to achieve the purpose with improvement recommendations to Level 2 namely Managed Process.
\end{abstract}

\section{Pendahuluan}

Sejak diberlakukannya UU No. 23 tahun 2014 tentang Pemerintahan Daerah terkait tanggung jawab pendidikan, kewenangan pengelolaan SMA/SMK dilimpahkan ke pihak provinsi [1]. Dengan pelaksanaannya dimulai pada tahun 2017, sehingga hal ini berdampak pada banyak hal, salah satu diantaranya adalah sistem pelayanan administratif yang dilakukan oleh provinsi ke SMA/SMK daerah masing-masing dengan implementasi e-government. Tujuan implementasi $e$ Government di suatu organisasi difungsikan untuk meningkatkan efisiensi, efektivitas, transparansi dan akuntabilitas penyelenggaraan pemerintahan dan pelayanan publik [6].

Dengan implementasi e-government di tingkat provinsi dipandang lebih efektif untuk menjembatani hubungan administratif baik dari pihak provinsi dengan SMK maupun sebaliknya. Dampaknya di semua daerah masing-masing SMK harus mempersiapkan dukungan sarana (infrastruktur) TI (teknologi informasi) yang memadai, dan sumber daya manusia yang berkompetensi pada bidang TI. Dengan hal ini, maka perlu adanya peninjauan tata kelola TI yang dilakukan di masing-masing SMK daerah. Tata kelola TI merupakan salah satu pendorong utama dalam transformasi proses bisnis menuju good governance [4]. Penggunaan sarana TI memberikan pengaruh penting untuk mencapai tujuan visi, dan misi bagi organisasi, dengan cara melakukan evaluasi, salah satunya dengan adanya pengukuran secara berkala [3].

Sebagai aset penting dengan nilai investasi, dan resiko yang tinggi, TI membutuhkan tata kelola yang baik dalam rangka mencapai tujuan organisasi [5]. Penerapan TI di organisasi dapat dilakukan dengan baik apabila ditunjang dengan manajemen konsep tata kelola TI mulai perencanaan sampai dengan proses implementasi. Penerapan TI tidak selalu identik selaras dengan perkembangan organisasi, namun dapat juga mendukung organisasi untuk tetap bertahan di tengah-tengah persaingan. TI sebaiknya harus dikelola selayaknya sebagai salah satu aset dari organisasi.

Peninjauan tata kelola TI melibatkan banyak unsur, unsur yang mendukung layanan data e-government diantanya 
adalah sumberdaya manusia (SDM) sebagai pelaku, dan aset TI sebagai perangkat kerasnya. Sedangkan untuk mengetahui kondisi tata kelola TI di SMK perlu adanya suatu penilaian tingkat kemampuan (capability level). Adapun capability level digunakan sebagai rujukan awal untuk membuat rekomendasi perbaikan secara bertahap khususnya dukungan TI terhadap pencapaian tujuan organisasi. COBIT merupakan salah satu framework yang sering digunakan oleh para auditor terutama auditor TI sebagai alat yang komprehensif untuk menciptakan tata kelola TI pada suatu organisasi [2]. Adapun COBIT 5 merupakan kerangka menyeluruh yang dapat membantu organisasi dalam mencapai tujuannya untuk tata kelola dan manajemen TI. Secara sederhana COBIT 5 membantu organisasi menciptakan nilai optimal dari TI dengan cara menjaga keselarasan antara mendapatkan keuntungan, mengoptimalkan tingkat resiko, dan penggunaan sumbar daya yang ada [5].

Berdasarkan uraian diatas, maka rumusan masalah penelitian ini adalah bagaimana tingkat kemampuan tata kelola TI khususnya unsur pengelolaan sumberdaya manusia TI dan aset TI di SMK (dibatasi SMK di kabupaten Madiun). Sedangkan tujuan penelitian ini adalah untuk mengetahui tingkat kemampuan tata kelola TI di SMK pada unsur pengelolaan sumberdaya manusia TI dan aset TI.

\section{METODE PENELITIAN}

Penelitian ini menggunakan framework COBIT 5 pada sub domain (proses) APO07 dan BAI09, tujuan dari masingmasing sub domain adalah sebagai berikut :

1) Proses APO07 Manage Human Resource bertujuan menyediakan pendekatan terstruktur untuk memastikan penataan, penempatan, ketrampilan sumber daya manusia secara optimal.

2) Proses BAI09 Manage Aset bertujuan pengelolaan aset, khususnya pada aset TI. Fokus dari pengelolaan aset diantaranya, identifikasi seluruh aset TI, pembiayaan operasional yang optimal, serta mengelola lisensi software.

Metodologi dalam penelitian ini diawali dari studi pustaka hingga rekomendasi perbaikan. Tahapan penelitian lebih jelasnya ditunjukkan seperti pada Gambar 1.

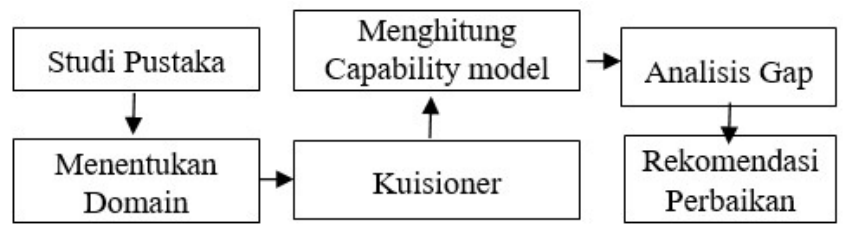

Gambar 1. Alur penelitian

Berikut tahapan dalam alur penelitian adalah :

1) Melakukan studi kepustakaan terkait infrastruktur TI SMK (SMK di kabupaten madiun), dan juga tentang manajemen audit tata kelola COBIT 5 dari jurnal.
2) Menentukan domain pada COBIT 5 yang sesuai dengan permasalahan infrastruktur TI di SMK, yaitu sub domain (proses) APO07 dan BAI09.

3) Membuat kuisioner berdasarkan aktifitas pada proses APO07 dan BAI09 untuk disebarkan ke responden yang berkepentingan.

4) Menghitung setiap aktifitas pada proses APO07 dan BAI09 menggunakan PAM (Procces Assesment Model) untuk mengetahui level instansi.

5) Menentukan analisis gap mengacu pada model PAM dan ISO 15504-2, 2003.

6) Memberikan rekomendasi perbaikan tata kelola TI mengacu model PAM.

\section{HASIL DAN PEMBAHASAN}

Pada bagian ini peneliti akan membahas hasil yang diperoleh dari sub domain (proses) APO07 dan BAI09. Adapun hasil yang diperoleh dari masing-masing proses adalah sebagai berikut.

\section{A. Proses APO07 Manage Human Resource}

Pada sub domain (proses) APO07 manage human resource terdapat enam aktifitas dengan hasil level kapabilitas dari proses APO07 beserta aktifitasnya disajikan dalam Tabel 1.

TABEL 1.

LEVEL KAPABILITAS APO07

\begin{tabular}{|l|c|c|}
\hline $\begin{array}{c}\text { Sub domain } \\
\text { (activity) }\end{array}$ & $\begin{array}{c}\text { Procces } \\
\text { atttribut }\end{array}$ & $\begin{array}{c}\text { Level } \\
\text { kapabilitas }\end{array}$ \\
\hline APO07.1 & $2.2(\mathrm{~L})$ & 2 \\
\hline APO07.2 & $2.1(\mathrm{~L})$ & 1 \\
\hline APO07.3 & $2.2(\mathrm{~L})$ & 2 \\
\hline APO07.4 & $2.1(\mathrm{~L})$ & 1 \\
\hline APO07.5 & $2.1(\mathrm{~L})$ & 1 \\
\hline APO07.6 & $2.1(\mathrm{~L})$ & 1 \\
\hline Rata-rata & 1,3 \\
\hline
\end{tabular}

Sumber: Data yang diolah, Tahun 2018

Berdasarkan Tabel 1, diketahuai level kapabilitas masingmasing activity sub domain APO07 rata-rata mencapai 1,3. Secara keseluruhan pada proses APO07 masih pada level 1 Performed Process.

\section{APO07.01 Maintain adequate and approriate staffing}

Pada aktititas ini rata-rata telah mencapai level 2.2 (L) work product management skala (L) largely achieved, maka level kapabilitas pada aktifitas ini adalah level 2 managed procces. Adanya perencanaan rekrutmen SDM baru yang dibutuhkan menjelang tahun ajaran baru, sebagian besar instansi juga mengevaluasi kebutuhan SDM.

\section{APO07.02 Identify key IT personnel}

Pada aktifitas ini rata-rata masih mencapai level 2.1 performance management skala (L) largely achieved, maka 
level kapabilitas pada aktifitas ini adalah level 1 Performed Process. Adanya kegiatan identifikasi SDM, Jumlah staf TI yang kompeten sesuai kebutuhan layanan TI instansi masih sedikit. Telah ada kegiatan workshop untuk meningkatkan kompetensi SDM TI walapun tidak kontinu.

\section{APO07.03 Maintain the skills and competencies of personel}

Pada aktitfitas ini rata-rata telah mencapai level 2.2 work product management skala (L) largely achieved, maka level kapabilitas pada aktifitas ini adalah level 2 managed procces. Adanya kegiatan pendataan atau identifikasi kompetensi masing-masing staf TI, adanya pendataan jobdesc masingmasing staf sesuai kompetensinya.

\section{APO07.04 Evaluate employee job performance}

Pada aktifitas ini rata-rata masih mencapai level 2.1 performance management skala (L) largely achieved, maka level kapabilitas pada aktifitas ini adalah level 1 Performed Process. Evaluasi kinerja staf SDM telah dilakukan secara global, belum merujuk ke tujuan instansi. Sebagian instansi telah memiliki rencana evaluasi kinerja secara individu.

\section{APO07.05 Plan and track the usage of IT and business human resource}

Pada aktifitas ini rata-rata masih mencapai level 2.1 performance management skala (L) largely achieved, maka level kapabilitas pada aktifitas ini adalah level 1 Performed Process. Adanya surat resmi terkait tugas dan tanggungjawab masing-masing staf TI mengenai layanan TI. Sebagian instansi melakukan perencanaan kebutuhan layanan TI saat ini dan masa yang akan datang.

\section{APO07.06 Manage contract staff}

Pada aktifitas ini rata-rata masih mencapai level 2.1 performance management skala (L) largely achieved, maka level kapabilitas pada aktifitas ini adalah level 1 Performed Process. Adanya perjanjian kontrak secara umum kurun waktu 1 tahun bagi SDM status kontrak, namun belum mencantumkan unsur kompetensi TI didalamnya.

\section{B. Proses BAI09 Manage Assets}

Deskripsi dari proses ini adalah pengelolaan aset, khususnya pada asset asset TI. Fokus dari pengelolaan aset diantaranya, identifikasi seluruh aset TI, pembiayaan operasional yang optimal, serta megelola lisensi software. Sedangkan hasil level kapabilitas dari proses BAO09 beserta aktifitasnya disajikan dalam Tabel 2.

TABEL 2.

LEVEL KAPABILITAS BAI09

\begin{tabular}{|l|l|c|}
\hline $\begin{array}{c}\text { Sub domain } \\
\text { (activity) }\end{array}$ & \multicolumn{1}{|c|}{$\begin{array}{c}\text { Procces } \\
\text { atttribut }\end{array}$} & $\begin{array}{c}\text { Level } \\
\text { kapabilitas }\end{array}$ \\
\hline BAI09.1 & $2.2(\mathrm{~L})$ & 2 \\
\hline BAI09.2 & $2,1(\mathrm{P})$ & 1 \\
\hline BAI09.3 & $2,1(\mathrm{P})$ & 1 \\
\hline
\end{tabular}

\begin{tabular}{|l|l|c|}
\hline BAI09.4 & $2,1(\mathrm{P})$ & 1 \\
\hline BAI09.5 & $2.1(\mathrm{P})$ & 1 \\
\hline Rata-rata & 1,2 \\
\hline
\end{tabular}

Sumber: Data yang diolah, Tahun 2018

Berdasarkan Tabel 2, diketahuai level kapabilitas masingmasing activity sub domain BAI09 rata-rata mencapai 1,2. Secara keseluruhan pada proses BAI09 masih pada level 1 Performed Process.

\section{BAI09.01 Identify and record current assets)}

Pada aktititas ini rata-rata telah mencapai level 2.2 (L) work product management, skala (L) largely achieved, maka level kapabilitas pada activity proses ini adalah level level 2 managed procces. Terbukti dengan adanya kegiatan sebagian besar aset TI telah teridentifikasi dan dicatat keberadaannya, serta adanya monitoring dan pelaporan identifikasi aset TI.

\section{BAI09.02 (Manage cricital assets)}

Pada aktititas ini rata-rata masih mencapai level 2.1 (P) performance management skala $(\mathrm{P})$ partially achieved maka level kapabilitas pada activity proses ini adalah level 1 Performed Process. Terbukti dengan hanya ada kegiatan pengidentifikasian aset TI yang dianggap sangat penting atau vital.

\section{BAI09.03 (Manage the asset life cycle)}

Pada aktititas ini rata-rata masih mencapai level 2.1 (P) performance management skala $(\mathrm{P})$ partially achieved maka level kapabilitas pada activity proses ini adalah level 1 Performed Process. Terbukti dengan adanya kegiatan pengelolaan aset yang rusak dan dapat diperbaiki kembali, atau pemusnahan aset yang sudah tidak terpakai.

\section{BAI09.04 (Optimise asset costs)}

Pada aktititas ini rata-rata masih mencapai level 2.1 (P) performance management skala $(\mathrm{P})$ partially achieved maka level kapabilitas pada activity proses ini adalah level 1 Performed Process. Terbukti dengan adanya kegiatan peninjauan seluruh basis aset yang masih layak dipakai secara teratur guna mengidentifikasi mengoptimalkan keuangan instansi.

\section{BAI09.05 (Manage License)}

Pada aktititas ini rata-rata masih mencapai level 2.1 (P) performance management skala $(\mathrm{P})$ partially achieved maka level kapabilitas pada activity proses ini adalah level 1 Performed Process. Terbukti dengan adanya kegiatan sebagian kecil instansi telah mendapatkan lisensi atas perangkat lunak yang digunakan.

\section{Analisis Gap dan Rekomendasi}

Analisis gap mengacu pada model PAM dan ISO 15504-2, 2003, perbaikan dapat dilakukan satu tingkat diatasnya 
apabila proses atribut (PA) berada pada level largely achieved (L), atau fully achieved (F). Jika masih berada diposisi bawahnya, not achieved $(N)$ atau partially achieved $(P)$, maka belum dapat naik ke tahap berikutnya. Analisis gap setiap activity pada sub domain ditujukkan pada Gambar 2.

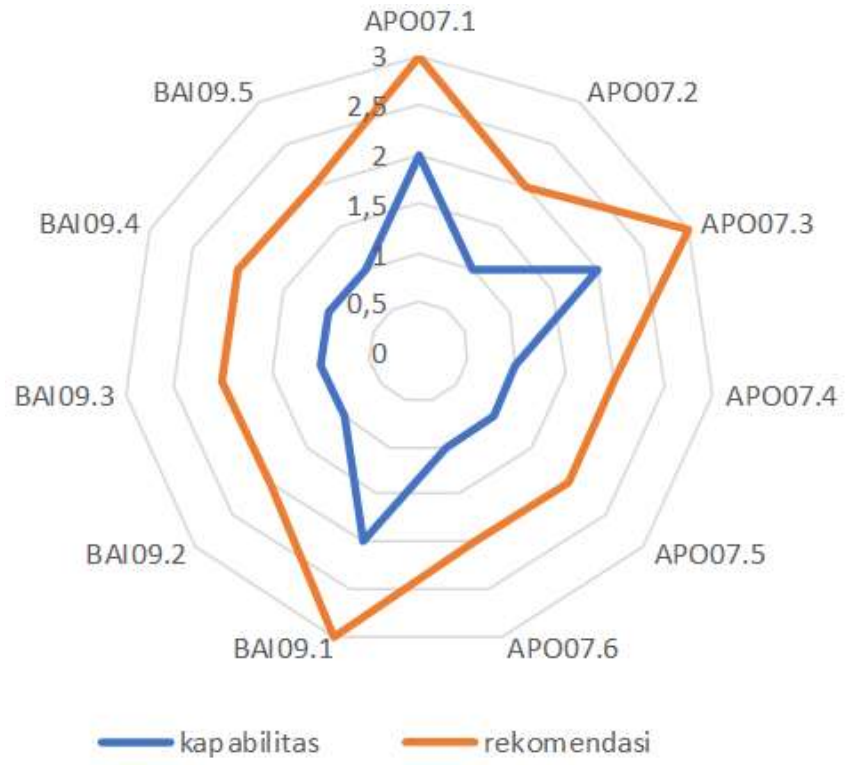

Gambar 2. Grafik analisisi gap

\section{Rekomendasi Perbaikan}

Berikut dibuat rekomendasi perbaikan kurun waktu tiga tahun, rekomendasi level kapabilitas disesuaikan dengan yang diperlukan dalam waktu dekat (tiga tahun kedepan). Masingmasing rekomendasi perbaikan beserta tahun pelaksanaanya ditunjukkan pada Tabel 3. Rekomendasi proses APO07 dan tabel 4. Rekomendasi proses BAI09.

TABEL 3.

REKOMENDASI PROSES APO07 (MANAGE HUMAN RESOURCE)

\begin{tabular}{|c|c|c|c|c|c|}
\hline \multirow[t]{2}{*}{$\begin{array}{l}\text { Sub domain } \\
\text { (activity) }\end{array}$} & \multirow[t]{2}{*}{ D } & \multirow[t]{2}{*}{ Uraian } & \multicolumn{3}{|c|}{$\begin{array}{c}\text { Rencana } \\
\text { Pelaksanaan } \\
\text { Tahun Ke }\end{array}$} \\
\hline & & & 1 & 2 & 3 \\
\hline \multirow{2}{*}{$\begin{array}{l}\text { APO07.01 } \\
\text { (Maintain } \\
\text { adequate and } \\
\text { approriate } \\
\text { staffing) }\end{array}$} & 3 & $\begin{array}{l}\text { Dibuatnya SOP } \\
\text { peggunaan SDM TI } \\
\text { dari pihak ketiga } \\
\text { (outsorcing). }\end{array}$ & & $\sqrt{ }$ & \\
\hline & 3 & $\begin{array}{l}\text { Monitoring } \\
\text { pelaksanaan SDM } \\
\text { dari pihak ketiga. }\end{array}$ & & & $\sqrt{ }$ \\
\hline \multirow[t]{2}{*}{$\begin{array}{l}\text { APO07.02 } \\
\text { (Identify key } \\
\text { IT personnel) }\end{array}$} & 2 & $\begin{array}{l}\text { Perencanaan agenda } \\
\text { rutin sharing } \\
\text { knowledge dari } \\
\text { SDM internal yang } \\
\text { telah kompeten. }\end{array}$ & & $\sqrt{ }$ & \\
\hline & 2 & $\begin{array}{l}\text { Monitoring } \\
\text { kegiatan sharing } \\
\text { knowledge internal. }\end{array}$ & & & $\sqrt{ }$ \\
\hline
\end{tabular}

\begin{tabular}{|c|c|c|c|c|c|}
\hline \multirow[t]{2}{*}{$\begin{array}{l}\text { Sub domain } \\
\text { (activity) }\end{array}$} & \multirow[t]{2}{*}{ 总 } & \multirow[t]{2}{*}{ Uraian } & \multicolumn{3}{|c|}{$\begin{array}{c}\text { Rencana } \\
\text { Pelaksanaan } \\
\text { Tahun Ke }\end{array}$} \\
\hline & & & 1 & 2 & 3 \\
\hline & 3 & $\begin{array}{l}\text { Mengidentifikasi } \\
\text { peningkatan } \\
\text { kompetensi SDM } \\
\text { hasil sharing } \\
\text { knowledge. }\end{array}$ & & & \\
\hline & 3 & $\begin{array}{l}\text { Monitoring } \\
\text { peningkatan } \\
\text { kompetensi SDM } \\
\text { setelah sharing } \\
\text { knowledge internal } \\
\end{array}$ & & & \\
\hline \multirow{4}{*}{$\begin{array}{l}\text { 3. APO07.03 } \\
\text { (Maintain } \\
\text { the skills and } \\
\text { competencies } \\
\text { of personel) }\end{array}$} & 2 & $\begin{array}{l}\text { Perencanaan } \\
\text { kebutuhan } \\
\text { kompetensi tiap staf } \\
\text { tahun mendatang. }\end{array}$ & $\sqrt{ }$ & & \\
\hline & 2 & $\begin{array}{l}\text { Mengirim staf } \\
\text { untuk ikut } \\
\text { workshop sesuai } \\
\text { yang direncanakan. }\end{array}$ & $\sqrt{ }$ & & \\
\hline & 3 & $\begin{array}{l}\text { Merencanakan staf } \\
\text { mendapatkan } \\
\text { sertifikat } \\
\text { kompetensi tingkat } \\
\text { lanjutan. }\end{array}$ & & & $\sqrt{ }$ \\
\hline & 3 & $\begin{array}{l}\text { Memonitoring } \\
\text { pelaksanaan } \\
\text { sertifikasi } \\
\text { kompetensi staf. }\end{array}$ & & & $\sqrt{ }$ \\
\hline \multirow[t]{4}{*}{$\begin{array}{l}\text { APO07.04 } \\
\text { (Evaluate } \\
\text { employee job } \\
\text { performance) }\end{array}$} & 2 & $\begin{array}{l}\text { Perencanaan SOP } \\
\text { evalusi kinerja } \\
\text { individu merujuk ke } \\
\text { visi instansi. }\end{array}$ & & $\sqrt{ }$ & \\
\hline & 2 & $\begin{array}{l}\text { Mengevaluasi hasil } \\
\text { evaluasi kinerja } \\
\text { individu. }\end{array}$ & & $\sqrt{ }$ & \\
\hline & 3 & $\begin{array}{l}\text { Penetapan standart } \\
\text { tanggungjawab } \\
\text { kinerja spesifik tiap } \\
\text { individu sesuai } \\
\text { kompetensinya. }\end{array}$ & & & $\sqrt{ }$ \\
\hline & 3 & $\begin{array}{l}\text { Mengevaluasi hasil } \\
\text { pelaksanaan SOP } \\
\text { kinerja individu. }\end{array}$ & & & $\sqrt{ }$ \\
\hline \multirow[t]{2}{*}{$\begin{array}{l}\text { APO07.05 } \\
\text { (Plan and } \\
\text { track the } \\
\text { usage of IT } \\
\text { and business } \\
\text { human } \\
\text { resource) }\end{array}$} & 2 & $\begin{array}{l}\text { Perencanaan } \\
\text { kebutuhan SDM } \\
\text { beserta spesifik } \\
\text { kompetensi sesuai } \\
\text { kebutuhan TI masa } \\
\text { depan. }\end{array}$ & & $\sqrt{ }$ & \\
\hline & 2 & $\begin{array}{l}\text { Mengevaluasi hasil } \\
\text { kebutuhan SDM } \\
\text { supaya sesuai } \\
\text { harapan. }\end{array}$ & & & $\sqrt{ }$ \\
\hline
\end{tabular}




\begin{tabular}{|c|c|c|c|c|c|}
\hline \multirow[t]{2}{*}{$\begin{array}{l}\text { Sub domain } \\
\text { (activity) }\end{array}$} & \multirow[t]{2}{*}{ d } & \multirow[t]{2}{*}{ Uraian } & \multicolumn{3}{|c|}{$\begin{array}{c}\text { Rencana } \\
\text { Pelaksanaan } \\
\text { Tahun Ke }\end{array}$} \\
\hline & & & 1 & 2 & 3 \\
\hline & 3 & $\begin{array}{l}\text { Mengidentifikasi } \\
\text { kekurangan SDM } \\
\text { yang kompeten } \\
\text { yang perlu dimiliki } \\
\text { instansi. }\end{array}$ & & $\sqrt{ }$ & \\
\hline & 3 & $\begin{array}{l}\text { Merencanakan hasil } \\
\text { identifikasi } \\
\text { kebutuhan SDM } \\
\text { yang kompeten. }\end{array}$ & & & $\sqrt{ }$ \\
\hline \multirow[t]{4}{*}{$\begin{array}{l}\text { APO07.06 } \\
\text { (Manage } \\
\text { contract } \\
\text { staff) }\end{array}$} & 2 & $\begin{array}{l}\text { Bagian rekrutmen } \\
\text { SDM melibatkan } \\
\text { orang TI sehingga } \\
\text { sesuai kompetensi } \\
\text { SDM baru yang } \\
\text { dibutuhkan. }\end{array}$ & $\sqrt{ }$ & & \\
\hline & 2 & $\begin{array}{l}\text { Melibatakan orang } \\
\text { TI dalam test calon } \\
\text { SDM. }\end{array}$ & $\sqrt{ }$ & & \\
\hline & 3 & $\begin{array}{l}\text { Adanya unsur } \\
\text { penguasaan TI } \\
\text { dalam kontrak kerja } \\
\text { untuk SDM baru. }\end{array}$ & & $\sqrt{ }$ & \\
\hline & 3 & $\begin{array}{l}\text { Memonitoring } \\
\text { pelaksanaan hasil } \\
\text { rekrutmen SDM } \\
\text { baru, mengevaluasi } \\
\text { supaya sesuai } \\
\text { harapan. }\end{array}$ & & & $\sqrt{ }$ \\
\hline
\end{tabular}

TABEL 4.

REKOMENDASI PROSES BAI09 (MANAGED ASSET)

\begin{tabular}{|c|c|c|c|c|c|}
\hline \multirow{2}{*}{$\begin{array}{c}\text { Sub } \\
\text { domain } \\
\text { (activity) }\end{array}$} & \multirow[t]{2}{*}{$\begin{array}{l}\overline{0} \\
0 \\
0 \\
\end{array}$} & \multirow[t]{2}{*}{ Uraian } & \multicolumn{3}{|c|}{$\begin{array}{c}\text { Rencana } \\
\text { Pelaksanaan } \\
\text { Tahun Ke }\end{array}$} \\
\hline & & & 1 & 2 & 3 \\
\hline \multirow{4}{*}{$\begin{array}{l}\text { BAI09.01 } \\
\text { Identify } \\
\text { and } \\
\text { record } \\
\text { current } \\
\text { assets }\end{array}$} & 2 & $\begin{array}{l}\text { Dibuatnya SOP untuk } \\
\text { mendokumentasikan } \\
\text { aset TI hingga detail } \\
\text { kondisinya. }\end{array}$ & $\sqrt{ }$ & & \\
\hline & 2 & $\begin{array}{l}\text { Pendokumentasian } \\
\text { aset TI dimonitoring } \\
\text { pelaksanaanya secara } \\
\text { berkala. }\end{array}$ & $\sqrt{ }$ & & \\
\hline & 3 & $\begin{array}{l}\text { Dibuatnya prosedur } \\
\text { kebutuhan aset selaras } \\
\text { dengan kebutuhan } \\
\text { layanan TI instansi. }\end{array}$ & & $\sqrt{ }$ & \\
\hline & 3 & $\begin{array}{l}\text { Pelaksanaan } \\
\text { kebutuhan aset yang } \\
\text { selaras kebutuhan } \\
\text { layanan TI }\end{array}$ & & $\sqrt{ }$ & \\
\hline
\end{tabular}

\begin{tabular}{|c|c|c|c|c|c|}
\hline \multirow[t]{2}{*}{$\begin{array}{c}\text { Sub } \\
\text { domain } \\
\text { (activity) }\end{array}$} & \multirow[t]{2}{*}{$\begin{array}{l}\bar{d} \\
\text { d] }\end{array}$} & \multirow[t]{2}{*}{ Uraian } & \multicolumn{3}{|c|}{$\begin{array}{c}\text { Rencana } \\
\text { Pelaksanaan } \\
\text { Tahun Ke }\end{array}$} \\
\hline & & & 1 & 2 & 3 \\
\hline & & $\begin{array}{l}\text { dimonitoring } \\
\text { pelaksanaanya. }\end{array}$ & & & \\
\hline \multirow[t]{4}{*}{$\begin{array}{l}\text { BAI09.02 } \\
\text { Manage } \\
\text { cricital } \\
\text { assets }\end{array}$} & 2 & $\begin{array}{l}\text { Dibuatnya SOP } \\
\text { pengelolaan rutin aset } \\
\text { TI instansi yang } \\
\text { dianggap penting } \\
\text { (vital). }\end{array}$ & & $\sqrt{ }$ & \\
\hline & 2 & $\begin{array}{l}\text { Dimonitoring } \\
\text { pelaksanaan SOP } \\
\text { pengelolaan aset TI } \\
\text { yang dianggap penting } \\
\text { (vital). }\end{array}$ & & $\sqrt{ }$ & \\
\hline & 3 & $\begin{array}{l}\text { Perencanaan } \\
\text { keberadaan aset TI } \\
\text { yang vital, sehingga } \\
\text { support terhadap } \\
\text { layanan TI instansi } \\
\text { masa depan. }\end{array}$ & & & $\sqrt{ }$ \\
\hline & 3 & $\begin{array}{l}\text { Pemantauan dan } \\
\text { pencatatan keberadaan } \\
\text { aset TI yang dianggap } \\
\text { penting (vital), } \\
\text { sehingga support } \\
\text { untuk layanan TI } \\
\text { instansi } 5 \text { tahun } \\
\text { kedepan. }\end{array}$ & & & $\sqrt{ }$ \\
\hline \multirow[t]{4}{*}{$\begin{array}{l}\text { BAI09.03 } \\
\text { Manage } \\
\text { the asset } \\
\text { life cycle }\end{array}$} & 2 & $\begin{array}{l}\text { Dibuatnya SOP } \\
\text { pemusnahan aset TI } \\
\text { yang sudah tidak } \\
\text { terpakai. }\end{array}$ & $\sqrt{ }$ & & \\
\hline & 2 & $\begin{array}{l}\text { Monitoring } \\
\text { pelaksanaan } \\
\text { pemusnahan aset } \mathrm{TI} \text {. }\end{array}$ & $\sqrt{ }$ & & \\
\hline & 3 & $\begin{array}{l}\text { Adanya prosedur } \\
\text { pemilahan aset TI } \\
\text { yang bisa dihibahkan } \\
\text { ke pihak lain atau } \\
\text { dimusnahkan aset yang } \\
\text { sudah tidak terpakai. }\end{array}$ & & & $\sqrt{ }$ \\
\hline & 3 & $\begin{array}{l}\text { Monitoring terhadap } \\
\text { aset TI yang tidah } \\
\text { terpakai untuk } \\
\text { dihibahkan ke pihak } \\
\text { lain. }\end{array}$ & & & $\sqrt{ }$ \\
\hline \multirow[t]{2}{*}{$\begin{array}{l}\text { BAI09.04 } \\
\text { Optimise } \\
\text { asset } \\
\text { costs }\end{array}$} & 2 & $\begin{array}{l}\text { Dibuatnya SOP untuk } \\
\text { perbaikan/service } \\
\text { berkala aset TI, } \\
\text { sehingga menghemat } \\
\text { keuangan. }\end{array}$ & $\sqrt{ }$ & & \\
\hline & 2 & $\begin{array}{l}\text { Memonitoring } \\
\text { pelaksanaan SOP }\end{array}$ & $\sqrt{ }$ & & \\
\hline
\end{tabular}




\begin{tabular}{|c|c|c|c|c|c|}
\hline \multirow{2}{*}{$\begin{array}{c}\text { Sub } \\
\text { domain } \\
\text { (activity) }\end{array}$} & \multirow[t]{2}{*}{$\begin{array}{l}0 \\
0 \\
0 \\
\end{array}$} & \multirow[t]{2}{*}{ Uraian } & \multicolumn{3}{|c|}{$\begin{array}{c}\text { Rencana } \\
\text { Pelaksanaan } \\
\text { Tahun Ke }\end{array}$} \\
\hline & & & 1 & 2 & 3 \\
\hline & & $\begin{array}{l}\text { perbaikan aset TI } \\
\text { secara berkala. }\end{array}$ & & & \\
\hline & 3 & $\begin{array}{l}\text { Dibuatnya } \\
\text { dokumentasi untuk } \\
\text { menyelaraskan } \\
\text { layanan TI dengan } \\
\text { kebutuhan aset TI } \\
\text { sebagai } \\
\text { pendukungnya. }\end{array}$ & & $\sqrt{ }$ & \\
\hline & 3 & $\begin{array}{l}\text { Memonitoring } \\
\text { pelaksanaan } \\
\text { penyelarasan } \\
\text { layananan TI dan aset. }\end{array}$ & & & $\sqrt{ }$ \\
\hline \multirow[t]{4}{*}{$\begin{array}{l}\text { BAI09.05 } \\
\text { Manage } \\
\text { License }\end{array}$} & 2 & $\begin{array}{l}\text { Membuat SOP terkait } \\
\text { legalitas sebagian } \\
\text { software yang } \\
\text { dianggap vital. }\end{array}$ & & $\sqrt{ }$ & \\
\hline & 2 & $\begin{array}{l}\text { Mengawasi } \\
\text { pelaksanaan lisensi } \\
\text { software }\end{array}$ & & & $\sqrt{ }$ \\
\hline & 3 & $\begin{array}{l}\text { Mendapatkan lisensi } \\
\text { software secara } \\
\text { berkala. }\end{array}$ & & & $\sqrt{ }$ \\
\hline & 3 & $\begin{array}{l}\text { Memonitoring update } \\
\text { lisensi software yang } \\
\text { dipakai instansi. }\end{array}$ & & & $\sqrt{ }$ \\
\hline
\end{tabular}

\section{KESIMPULAN}

Mengacu pada Tabel 1 dan Tabel 2, tingkat kapabilitas tata kelola TI pada unsur pengelolaan sumberdaya manusia TI dan aset TI di SMK Madiun berada pada level Performed Process dimana kegiatan proses proses yang berkaitan dengan pengelolaan sumber daya dan aset TI telah diimplementasikan, namun masih sebagian kecil kegiatan yang dilanjutkan hingga ke monitoring. Perlu dilakukan tindaklanjut untuk mencapai tatakelola TI yang baik.

Instansi skala kecil masih sedikit yang peduli terhadap tata kelola TI, sehingga perlu dilakukan pemahaman terkait pentingnya evaluasi tata kelola TI di SMK sedini mungkin. Penelitian berikutnya dapat mengembangkan pada sub domain yang lain dari framework COBIT 5.

\section{UCAPAN TERIMA KASIH}

Peneliti mengucapkan terima kasih kepada Politeknik Negeri Madiun yang mendukung administrasi, dan Kemenristekdikti atas hibah pendanaan riset program Penelitian Dosen Pemula (PDP).

\section{DAFTAR PUSTAKA}

[1] Aivanni, N. (2017, 08 16). Mediaindonesia.com. Retrieved from mediaindonesia.com: http://mediaindonesia.com/read/detail/117828sma-smk-tetap-dikelola-pemprov-1.

[2] Andry, J., F., Christianto, K. Audit Menggunakan COBIT 4.1 dan COBIT 5 dengan Case Study. Yogyakarta: Teknosain.

[3] Ariyadi, D. (2017). Evaluasi Infrastruktur TI Menggunakan Framework COBIT 4.1. Fountain of Informatics Journal Volume 2, No. 2, November 2017.

[4] Novita, R., Nugroho, E., (2014). Sumaryono, S. Penilaian Tingkat Capability Tata Kelola TI pada Aspek Manajeman Sumber Daya Manusia. Seminar Nasional Teknologi Informasi dan Multimedia 2014, 2.07.41-46.

[5] Putri, R., E. (2015). Model Penilaian Kapabilitas Proses Optimasi Resiko TI Berdasarkan COBIT 5. Seminar Nasional Informatika, 252258.

[6] Romayah, S., Suroso, A.I., Ramadhan, A. (2014). Evaluasi Implementasi E-government di Instansi XYZ. Jurnal Aplikasi Manajemen (JAM) Vol 12 No 4, 612-620. 